\title{
Physiological tests in assessing of winter wheat gene pool for adaptability and productivity
}

Yessimbekova M.*, Suleimenova M., Mukin K.

Kazakh Research Institute of Agriculture and Plant Growing, Almalybak, Kazakhstan

*e-mail:minura.esimbekova@mail.ru

The predicted global climate change in the world is of particular importance for Kazakhstan, the main areas of agricultural production of which are characterized by high variability of environmental factors. According to the Second National Report on Climate Change (UNFCCC, 2009), the temperature regime in Kazakhstan changes mainly in the direction of warming. High temperature can be one of the main factors limiting the productivity of all agricultural crops, including wheat. In this regard, the understanding of physiological problems associated with stress caused by high temperature is of great importance. As an indirect selection criterion for heat tolerance, the CTD (canopy temperature depression) feature, calculated as the difference between the canopy temperature and the environment was used. According to the CTD value, the accessions were ranged from $11.4^{\circ} \mathrm{C}$ to $14.2^{\circ} \mathrm{C}$. The tendency to increase in productivity with an increase in $\mathrm{CTD}(\mathrm{r}=0.69)$ was revealed. The most productive was the variety Kharkovskaya-106 $\left(9.1 \mathrm{t} / \mathrm{ha}, \mathrm{CTD}=13.6^{\circ} \mathrm{C}\right)$. Monitoring of winter wheat gene pool using the "Green Seeker" (optical sensor) showed a change in the plant biomass index (NDVI) in more than $70 \%$ of the accessions, depending on: 1) the cultivation conditions (irrigation, rain fed); 2) year of study; 3) growth stage. A high NDVI value was observed on irrigation in the heading stage (0.50-0.82) and a decrease (0.34-0.73) during the grain filling period. In $25 \%$ of the accessions the high NDVI remained at the same level during the 2 measurement phases, which affected the yield. In rain fed conditions the NDVI value ranged from 0.20 to 0.39 . According to the indicators of photosynthetic activity, the accessions of winter wheat were divided into 3 groups: high, medium and low productivity. In relatively high-yielding varieties (5.0-7.7 t/ha), the assimilation surface ranged from 50.4 to 72.9 thousand $\mathrm{m}^{2} /$ ha. 